\title{
The abdication of Pope Mary III
}

\author{
...or, Galileo's revenge...
}

\section{D}

Robert J. Sawyer arth Vader's booming voice, still the network's trademark 600 years after its founding: "This is CNN."

And then the news anchor: "Our top story: Pope Mary III abdicated this morning. Giancarlo DiMarco, our correspondent in Vatican City, has the details. Giancarlo?"

"Thanks, Lisa. The unprecedented has indeed happened: after 312 years of service, Pope Mary III stepped down today. Traditionally, the conclave of Roman Catholic cardinals waits 18 days after the death of a pope before beginning deliberations to choose a successor, but Mary - who has returned to her birth name of Sharon Cheung - is alive and well, and so the members of the conclave have already been sealed inside the Vatican Palace, where they will remain until they've chosen Mary's replacement.

"Although no new pope has been elected for over 300 years, the traditional voting method will be used. We are now watching the Sistine Chapel for the smoke that indicates the ballots have been burned following a round of voting. And - Lisa, Lisa, it's happening right now! There's smoke coming out, and - no, you can hear the disappointment of the crowd. It's black smoke; that means no candidate has yet received the required majority of two-thirds plus one. But we'll keep watching."

"Thanks, Giancarlo. Let's take a look at Pope Mary's press conference, given earlier today."

Tight shot on Mary, looking only a tenth of her 400 years: "Since Vatican IV reaffirmed the principle of papal infallibility," she said, "and since I now believe that I was indeed in error 216 years ago when I issued a bull instructing Catholics to reject the evidence of the two Benmergui experiments, I feel compelled to step down ..."

"We're joined now in the studio by Joginder Singh, professor of physics at the University of Toronto. Dr Singh, can you explain the Benmergui experiments for our viewers?"

"Certainly, Lisa. The first proved that John Cramer's transactional interpretation of quantum mechanics, proposed in the late twentieth century, is in fact correct."

"And that means ...?"

"It means that the many-worlds interpretation is flat-out wrong: new parallel universes are not spawned each time a quantum event could go multiple ways. This is the one and only extant iteration of reality."

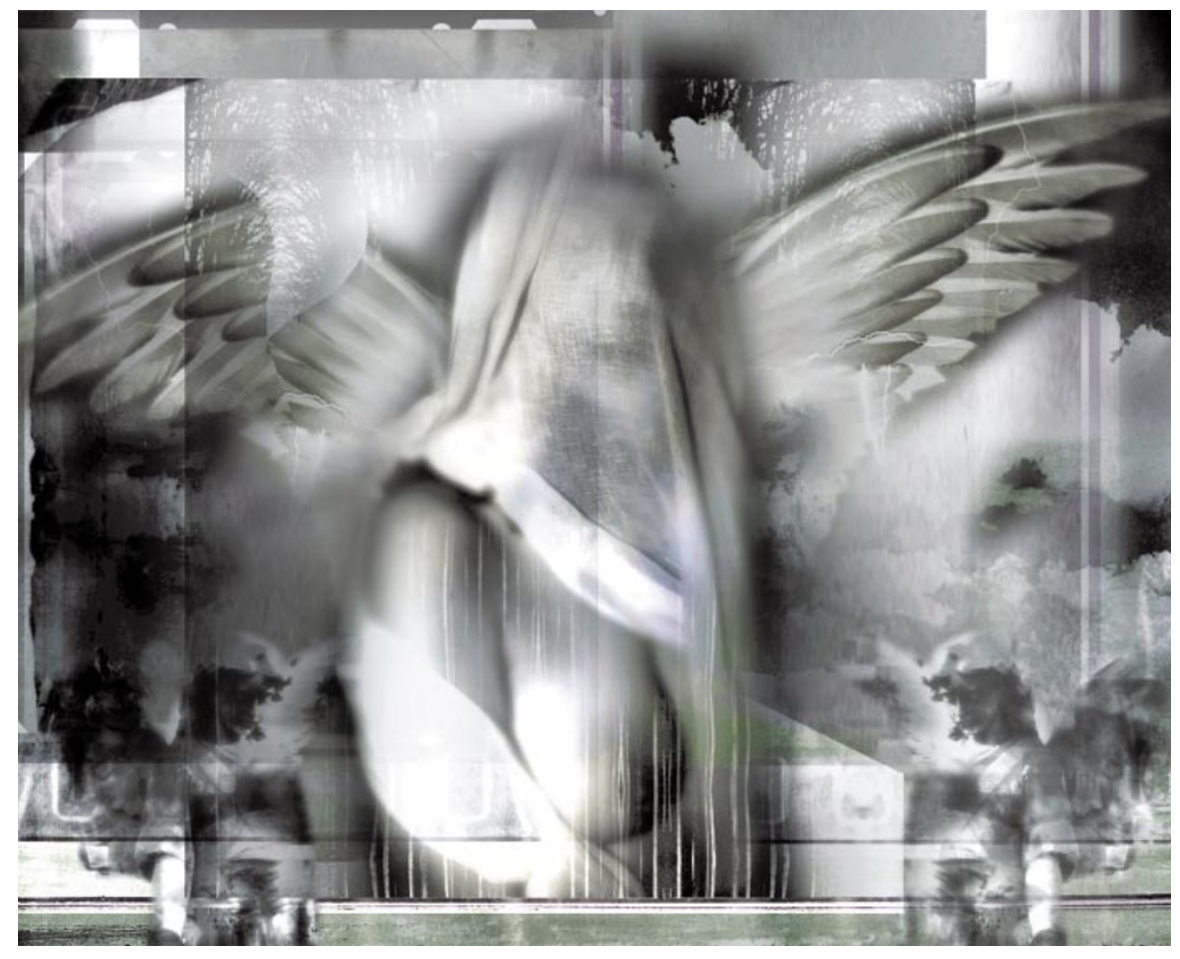

"And Dr Benmergui's second experiment?"

"It proved the current cycle of creation was only the seventh such ever; just six other Big Bang/Big Crunch oscillations preceded our current universe. The combined effect of these two facts led directly to Pope Mary's crisis of faith, specifically because they proved the existence of - one might as well use the word - God."

"How? I'm sure our viewers are scratching their heads ..."

"Well, you see, the observation, dating back to the twentieth century, that the fundamental parameters of the universe seem finetuned to an almost infinite degree specifically to give rise to life, could previously be dismissed as a statistical artefact caused by the existence of many contemporaneous parallel universes or a multitude of previous ones. In all of that, every possible combination would crop up by chance, and so it wouldn't be remarkable that there was a universe like this one - one in which the force of gravity is just strong enough to allow stars and planets to coalesce but not just a little bit stronger, causing the universe to collapse long before life could have developed. Likewise, the value of the strong nuclear force, which holds atoms together, seems finely tuned, as do the thermal properties of water, and on and on."

"So our universe is a very special place?

"Exactly. And since, as Kathryn Benmergui proved, this is the only current universe, and one of just a handful that have ever existed, then the life-generating properties of the very specific fundamental constants that define reality are virtually impossible to explain except as the results of deliberate design."

"But then why would Pope Mary resign? Surely, if science has proven the existence of a creator ...?"

Singh smiles. "Ah, but that creator is clearly not the God of the Bible or the Torah or the Qur'an. Rather, the creator is a physicist, and we are one of his or her experiments. Science hasn't reconciled itself with religion; it has superseded it, and -"

"I'm sorry to interrupt, Dr Singh, but our reporter in Vatican City has some breaking news. Giancarlo, over to you ...”

"Lisa, Lisa - the incredible is happening. At first I thought they were just tourists coming out of the Sistine Chapel, but they're not - I recognize Fontecchio and Leopardi and several of the others. But none of them are wearing robes; they're in street clothes. I haven't taken my eyes off the chapel: there's been no plume of white smoke, meaning they haven't elected a new leader of the They're coming outside, heading into St Peter's Square. The crowd is stunned, Lisa it can only mean one thing ..."

Nebula Award-winner Robert J. Sawyer's latest novel is Calculating God (Tor); http://www.sfwriter.com. church. But the cardinals are coming out. 